\title{
Granulomatous bronchiolitis with necrobiotic pulmonary nodules in Crohn's disease
}

\author{
Hugh J Freeman MD FRCPC ${ }^{1}$, Jennifer E Davis MBBS FRCPC ${ }^{2}$, Marcia E Prest MD FRCPC $^{3}$, Edward J Lawson MD FRCPC ${ }^{3}$
}

\begin{abstract}
HJ Freeman, JE Davis, ME Prest, EJ Lawson. Granulomatous bronchiolitis with necrobiotic pulmonary nodules in Crohn's disease. Can J Gastroenterol 2004;18(11):687-690.

A 37-year-old man with extensive Crohn's disease of the stomach, small and large intestine for almost a decade developed respiratory symptoms and radiological findings suggestive of pneumonia that failed to resolve with antibiotic treatment. Computed tomography scanning of his lungs showed extensive changes with cavitated parenchymal nodules. Histological evaluation of an open lung biopsy showed granulomatous bronchiolitis and pulmonary necrobiosis. Treatment with steroids and immunosuppression resulted in complete resolution of his clinical symptoms of pneumonia and abnormal computed tomography imaging changes. Granulomatous bronchiolitis and necrobiotic nodules may be a manifestation of Crohn's disease in the absence of microbial agents, including mycobacteria or fungal agents. While a multiplicity of complex pulmonary changes may occur in Crohn's disease, their clinical recognition and precise pathological definition may be particularly important if treatment with a biological agent, such as infliximab, is being considered.
\end{abstract}

Key Words: Bronchopleural fistula; Crohn's disease; Granulomatous bronchiolitis; Infliximab; Necrobiotic pulmonary nodules; Pulmonary tuberculosis

\section{Bronchiolite granulomateuse, nodules pul- monaires nécrobiotiques et maladie de Crohn}

\begin{abstract}
Un homme âgé de 37 ans, atteint, depuis presque dix ans, d'une maladie de Crohn étendue, touchant l'estomac, l'intestin grêle et le côlon, a présenté des symptômes respiratoires, et les examens radiologiques évoquaient une pneumonie, mais celle-ci n'a pas réagi au traitement antibiotique. Une tomodensitométrie des poumons a montré des changements importants, accompagnés de nodules cavitaires du parenchyme. On a procédé à une biopsie du poumon à ciel ouvert, et l'examen histologique a révélé la présence d'une bronchiolite granulomateuse et d'une nécrobiose pulmonaire. Un traitement composé de stéroïdes et d'immunodépresseurs a permis la disparition complète des symptômes cliniques de pneumonie et des changements anormaux révélés à la tomodensitométrie. Une bronchiolite granulomateuse, accompagnée de nodules nécrobiotiques peut être une manifestation de la maladie de Crohn en l'absence d'agents microbiens, y compris de mycobactéries et de champignons. La maladie de Crohn pouvant donner lieu à une multitude de changements pulmonaires complexes, il peut être particulièrement important de les reconnaître cliniquement et d'en préciser la nature histologique si un traitement à base d'agent biologique comme l'infliximab est envisagé.
\end{abstract}

$\mathrm{T}$ he pulmonary changes in patients with chronic inflammatory bowel diseases have been well described in the past two decades, and were recently reviewed (1-4). Most often, these have been associated with ulcerative colitis $(3,4)$, although significant pulmonary changes have also been rarely recorded in Crohn's disease $(3,4)$.

In Crohn's disease, changes usually develop after the intestinal disease is well established, but in some patients, the pulmonary disease preceded the intestinal changes (5-7). Earlier reports also suggested overlap between pulmonary granulomatous disease in Crohn's disease and sarcoidosis (8-11), but newer classifications have categorized the pulmonary changes in Crohn's disease as either airway or interstitial disease $(3,4)$. In some patients, mesalamine or other medications may be responsible, and differentiation of drug-induced versus diseaserelated changes may be difficult (12).

Cavitary lung lesions may also occur in Crohn's disease. Opportunistic infections with tuberculosis, Pneumocystis carinii and fungal infections should be considered, and aggressive immunosuppression may also predispose to cavitating malignancies, including lymphoma. In addition, vasculitis or metastatic Crohn's disease may cause cavitary lung lesions (13). Finally, necrobiotic pulmonary nodules may occur in patients with ulcerative colitis or predominantly Crohn's colitis $(14,15)$.

\section{CASE PRESENTATION}

A 37-year-old man was referred in August 1993 for investigation of diarrhea, which had been present for over 10 years. In June 1993, an ischiorectal abscess was drained at his community hospital. Later, periumbilical abdominal pain developed, associated with a $15 \mathrm{~kg}$ weight loss. An examination revealed a fatigued man with a weight of $69 \mathrm{~kg}$. There was no fever but tenderness was present in the right lower quadrant. Laboratory studies revealed anemia (hemoglobin $110 \mathrm{~g} / \mathrm{L}$ ), a normal white blood cell count and thrombocytosis of 493,000. Sedimentation rate was $48 \mathrm{~mm} / \mathrm{h}$. Serum iron studies showed $2 \%$ saturation while serum albumin was reduced to

${ }^{1}$ Department of Medicine, Division of Gastroenterology and ${ }^{2}$ Department of Laboratory Medicine, Division of Anatomical Pathology, University of

British Columbia, Vancouver; and Department of Medicine, Divisions of ${ }^{3}$ Gastroenterology and ${ }^{4}$ Respiratory Medicine, Surrey Memorial

Hospital, Surrey, British Columbia

Correspondence: Dr Hugh Freeman, Gastroenterology, University of British Columbia Hospital, 2211 Wesbrook Mall, Vancouver,

British Columbia V6T 2B5. Telephone 604-822-7216, fax 604-822-7236, e-mail hugfree@shaw.ca

Received for publication April 29, 2004. Accepted August 10, 2004 
$30 \mathrm{~g} / \mathrm{L}$. Red cell folate, serum vitamin $\mathrm{B}_{12}$, liver chemistry tests and renal function tests were normal. Fecal bacteriology and parasite studies were negative. Chest radiographs were normal but barium studies showed aphthoid ulcerations in the stomach with narrowing of the antrum and pylorus, thickened duodenal folds with diminished distensibility of the bulb, and irregular narrowing of the descending duodenum. Extensive ulceration and narrowing were present in the proximal jejunum and the distal $20 \mathrm{~cm}$ of the ileum, as well as the cecum and the ascending and transverse colon, which is consistent with multifocal involvement due to Crohn's disease. Endoscopy revealed a normal esophagus but gastric antral erosions were present along with linear and serpiginous duodenal ulceration; biopsies showed focally active gastritis with a gastric mucosal granuloma and a single focus of duodenal granulomatous inflammation. A flexible sigmoidoscopy and rectal biopsy were normal.

Initial treatment included a lactose-free diet, oral iron, omeprazole and oral mesalamine followed by an eight-week course of tapering prednisone.

By May 1994, his diarrhea and abdominal pain had resolved. His weight had increased by $6 \mathrm{~kg}$. His hemogram was normal but his serum iron studies still showed only $7 \%$ saturation and serum albumin was $31 \mathrm{~g} / \mathrm{L}$.

Diarrhea reappeared in June 1995 and a flexible sigmoidscopy showed scattered aphthoid ulcers in the rectum and sigmoid colon; a further course of oral prednisone was administered.

In March 1996, a colonoscopy showed ileal and cecal ulceration only. Biopsies showed nonspecific inflammatory changes but no granulomas.

In March 1997, diarrhea recurred with abdominal pain, vomiting and weight loss to $61 \mathrm{~kg}$. Endoscopic studies of the upper and lower gastrointestinal tract showed gastric, duodenal and ileocecal ulceration. Instead of oral prednisone, budesonide controlled ileal release $3 \mathrm{mg}$ twice a day was obtained through a compassionate release program (Astra Pharma, Canada), but it appeared to be ineffective in controlling symptoms over a period of six months.

From October 1997 to February 1998, a prolonged course of oral prednisone was provided. Repeated barium radiographic studies of his upper gastrointestinal tract showed a normal stomach but persistent strictures were present in the duodenum and ileum. Surgical treatment was refused and so metronidazole was initiated.

In early March 2000, cough, fever and further weight loss developed. Chest radiographs showed changes consistent with pneumonitis and his family physician prescribed azithromycin.

In June 2000, a helical computed tomography (CT) scan of the chest with contrast showed innumerable small nodular opacities in both lungs; the opacities were more numerous in the right upper and left lower lobes than elsewhere, and ranged in size up to $1 \mathrm{~cm}$. Small areas of cavitation were seen in these opacities and an infectious etiology including fungal or tuberculous pulmonary disease was suggested. Serological studies for rheumatoid factor, antinuclear antibodies, antineutrophil cytoplasmic antibodies (ANCA, including ANCA with a cytoplasmic staining pattern [c-ANCA]) and HIV were negative. A purified protein derivative test was negative. There was no known exposure to tuberculosis or histoplasmosis and no history of foreign travel or occupational exposure. There were no clinical features or familial history to suggest an underlying or concomitant connective tissue disorder such as rheumatoid arthritis. Bronchoscopy revealed nonspecific findings and a transbronchial biopsy was negative. Pulmonary function studies showed changes of severe obstructive lung disease in a pattern consistent with advanced emphysema. Open lung biopsy showed granulomatous bronchiolitis and necrobiotic nodules (Figures 1 to 6 ). Acid fast and silver stains were negative. Cultures for mycobacteria and fungi were negative. During hospitalization, his intestinal disease worsened with recurrent abdominal pain and diarrhea. An ischiorectal abscess developed, necessitating surgical drainage. There was a persistent bronchopleural fistula from the biopsy site and chest tube drainage persisted for over two months.

Eventually, his chest tube was spontaneously expelled with a coughing episode and his fistula closed. His respiratory symptoms improved with a course of prednisone, and a follow-up CT scan showed resolution of the bronchiolitis and nodular changes. Subsequent treatment for his intestinal disease has included oral metronidazole, ciprofloxacin and azathioprine.

\section{DISCUSSION}

Pulmonary complications in patients with inflammatory bowel disease are becoming increasingly recognized. Even in the absence of symptoms or reported radiological changes, over $50 \%$ of Crohn's disease patients have been documented with altered lung function (16). Indeed, very recent studies in patients with Crohn's disease using high resolution CT scanning showed that all patients had one or more abnormalities detected with this modern imaging method (17). Pathological pulmonary changes in Crohn's disease may be categorized as airway or interstitial parenchymal disease, and include infectious, noninfectious and drug-induced causes. This patient had dramatic radiographic and helical CT scan findings of extensive cavitating pulmonary parenchymal disease confirmed histologically, with an open lung biopsy that showed granulomatous bronchiolitis and necrobiosis. The latter feature has been rarely recorded in Crohn's disease $(14,15,18)$, usually with disease localized predominantly in the colon alone, or occasionally associated with pyoderma gangrenosum $(19,20)$. In this patient, extensive multifocal involvement of the stomach, small intestine and colon with Crohn's disease was defined without other extraintestinal changes, including dermatological complications.

In this patient, the duration of the lung disease before its eventual recognition and diagnosis was unknown, but may have been occult and prolonged because of intermittent courses of oral corticosteroids used to treat his intestinal symptoms over many years. In some patients with noninfectious pulmonary pathology in Crohn's disease, treatment with corticosteroids has been associated with resolution of the lung disease, and in this patient, may have indirectly and unknowingly ameliorated pulmonary changes. Eventually, in the absence of ongoing corticosteroids, respiratory symptoms became clinically evident, which led to more detailed pulmonary investigations and a precise diagnosis.

Although there is evidence from case studies that use of corticosteroids or other forms of immunosuppression may be useful to manage the necrobiotic pulmonary lesions in Crohn's disease, definition of cavitating pulmonary nodules raises the possibility of underlying pulmonary tuberculosis or another ubiquitious infectious agent. In this setting, the decision to use 


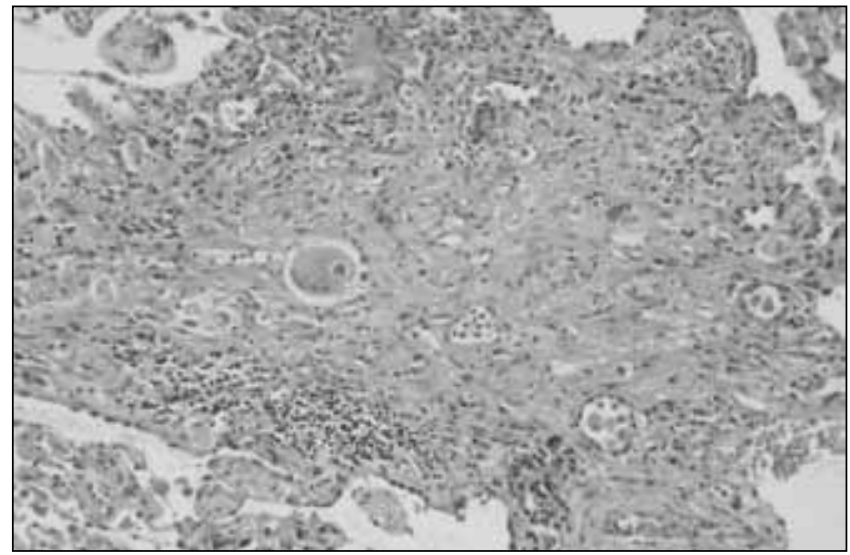

Figure 1) Non-necrotizing granuloma with a central scar. Pigmentladen macrophages are also present (hematoxylin and eosin stain, original magnification $\times 40$ )

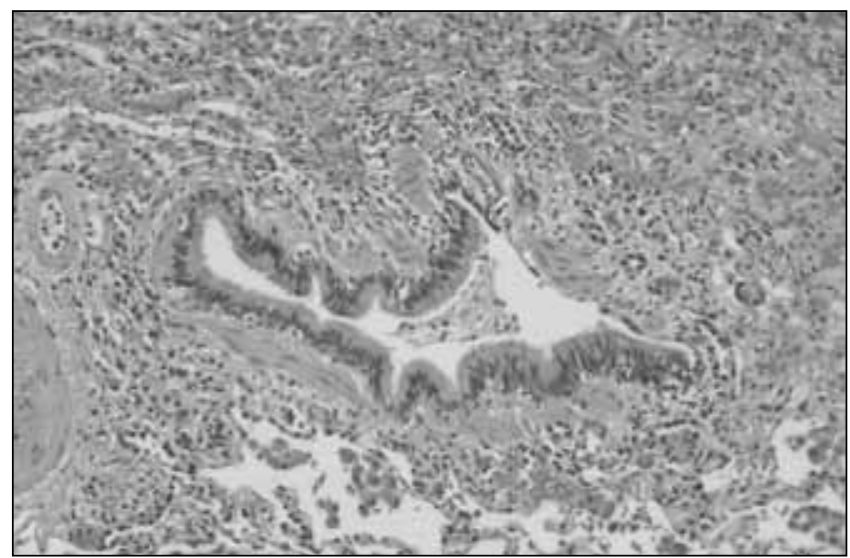

Figure 2) Bronchiolitis with destruction of some of the wall (hematoxylin and eosin stain, original magnification $\times 160$ )

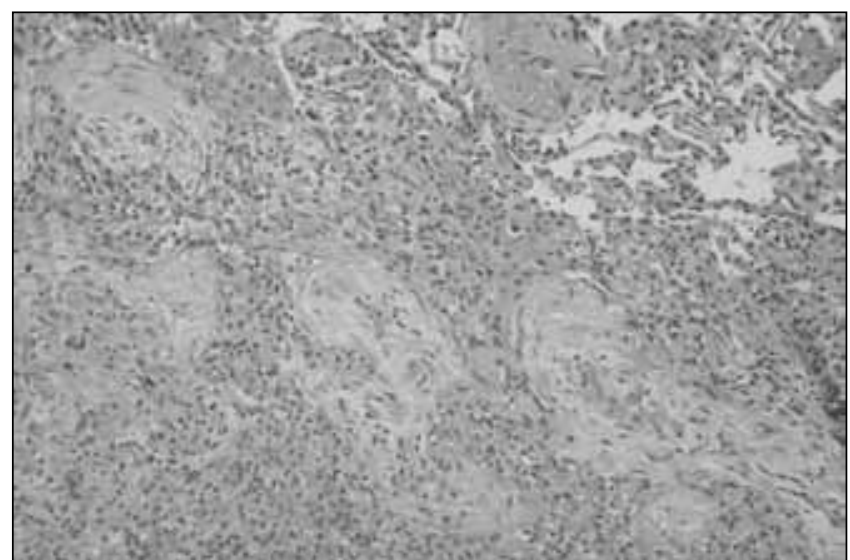

Figure 3) Bronchiolitis obliterans organizing pneumonia with mixed inflammation (hematoxylin and eosin stain, original magnification $\times 40$ )

immunosuppressive therapy is difficult. Here, infliximab therapy was also considered but it was thought not to be a safe option. There are a number of studies now documenting subsequent development of serious infections, including fatal tuberculous disease, histoplasmosis and other infections (21-23) as well as

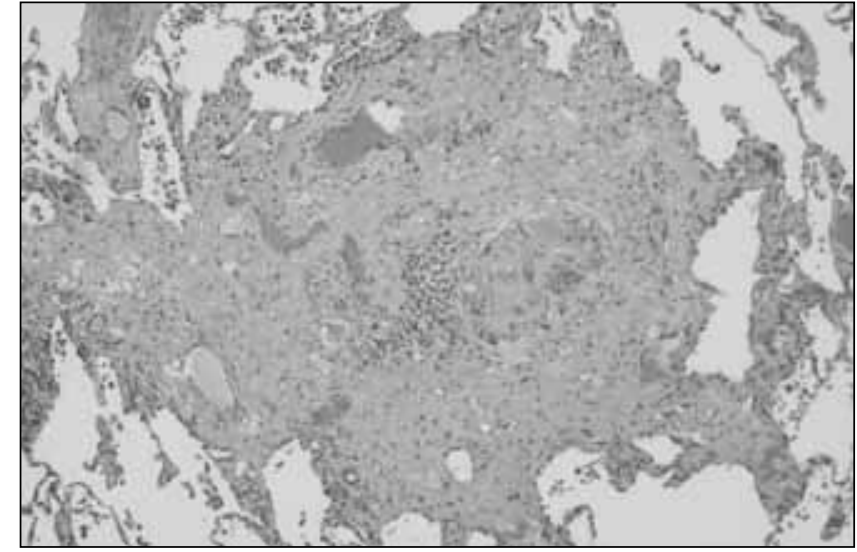

Figure 4) Stellate scar with a collection of giant cells in the centre (hematoxylin and eosin stain, original magnification $\times 40$ )

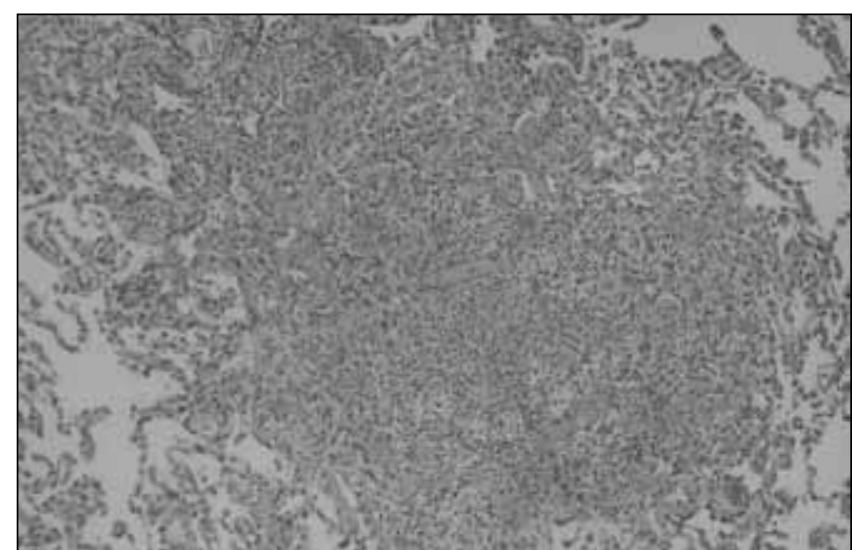

Figure 5) Neutrophilic inflammation and destruction of alveolar walls typical of necrobiotic lesion (hematoxylin and eosin stain, original magnification $\times 40$ )

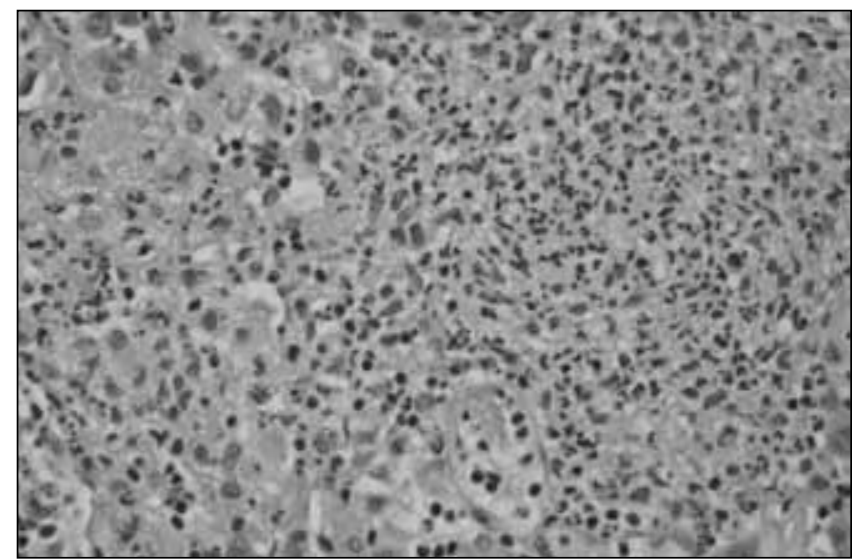

Figure 6) Higher power of necrobiotic lesion with central neutrophils, together with inflammation surrounding the blood vessel, possibly a secondary vasculitis (hematoxylin and eosin stain, original magnification $\times 100$ )

sterile pulmonary granulomas (24) following infliximab treatment. In contrast, there are also rare cases of resolution of noninfectious pulmonary disease $(25,26)$ with infliximab therapy. These apparently contradictory reports serve as a reminder that our understanding of the effects and risks of 
tumour necrosis factor-alpha inhibition remain limited and, despite recent reports of adverse events in large clinical experiences $(27,28)$, still require further elucidation and longer term monitoring.

ACKNOWLEDGEMENTS: The authors are grateful to the following physicians for their helpful input in the clinical management of this patient's pulmonary disorder: Dr R Blackmore, family physician, Langley, British Columbia; Dr D Grant, Department of Pathology and Dr A Valji, Department of Surgery, Surrey Memorial Hospital, Surrey, British Columbia; and Dr A Churg, Department of Pathology, University of British Columbia, Vancouver, British Columbia.

\section{REFERENCES}

1. Kraft SC, Earle RH, Roesler M, Esterly JR. Unexplained bronchopulmonary disease with inflammatory bowel disease. Arch Intern Med 1976;136:454-9.

2. Shah SM, Texter EC Jr, White HJ. Inflammatory bowel disease associated with granulomatous lung disease: Report of a case with endoscopic findings. Gastrointest Endosc 1976;23:98-9.

3. Camus P, Piard F, Ashcroft T, Gal AA, Colby TV. The lung in inflammatory bowel disease. Medicine 1993;72:151-83.

4. Storch I, Sachar D, Katz S. Pulmonary manifestations of inflammatory bowel disease. Inflamm Bowel Dis 2003;9:104-15.

5. Henrion F, Bretagne MC, Neimann L, Flechon PE, Canton P, Hoeffel JC. Pulmonary and cutaneous lesions and terminal ileitis in an 11-year-old child: An exceptional case. J Radiol 1982;63:123-6.

6. Calder CJ, Lacy D, Raafat F, Weller PH, Booth IW. Crohn's disease with pulmonary involvement in a 3 year old boy. Gut 1993;34:1636-8.

7. Al-Binali AM, Scott B, Al-Garni A, Montgomery M, Robertson M. Granulomatous pulmonary disease in a child: An unusual presentation of Crohn's disease. Pediatr Pulmonol 2003;36:76-80.

8. Dines DE, Green PA, DeRemee RA. Sarcoidosis associated with regional enteritis (Crohn's disease). Minn Med 1971;54:617-20.

9. Kraft SC. Crohn's disease and sarcoidosis. N Engl J Med 1971;285:1259-60.

10. Padilla AJ, Sparberg M. Regional enteritis and sarcoidosis in one patient. A case report. Gastroenterology 1972;63:153-60.

11. Gronhagen-Riska C, Fyhrquist F, Hortling L, Koskimies S. Familial occurrence of sarcoidosis and Crohn's disease. Lancet 1983;1:1287-8.

12. Foster RA, Zander DS, Mergo PJ, Valentine JF. Mesalamine-related lung disease: Clinical, radiographic and pathologic manifestations. Inflamm Bowel Dis 2003;9:308-15.
13. Lucero PF, Frey WC, Shaffer RT, Morris MJ. Granulomatous lung masses in an elderly patient with inactive Crohn's disease. Inflamm Bowel Dis 2001;7:256-9.

14. Faller M, Gasser B, Massard G, Pauli G, Quoix E. Pulmonary migratory infiltrates and pachypleuritis in a patient with Crohn's disease. Respiration 2000;67:459-63.

15. Golpe R, Mateos A, Perez-Valcarcel J, Lapena JA, Garcia-Figueiras $\mathrm{R}$, Blanco J. Multiple pulmonary nodules in a patient with Crohn's disease. Respiration 2003;70:306-9.

16. Kuzela L, Vavrecka A, Prikazska M, et al. Pulmonary complications in patients with inflammatory bowel disease. Hepatogastroenterology 1999;46:1714-9.

17. Songur N, Songur Y, Tuzun M, et al. Pulmonary function tests and high-resolution CT in the detection of pulmonary involvement in inflammatory bowel disease. J Clin Gastroenterol 2003;37:292-8.

18. Sanjeevi A, Roy HK. Necrobiotic nodules: A rare pulmonary manifestation of Crohn's disease. Am J Gastroenterol 2003;98:941-3.

19. Hickman JC, Lazarus GS. Pyoderma gangrenosum. A reappraisal of associated systemic diseases. Br J Dermatol 1980;102:235-7.

20. Kasuga I, Yanagisawa N, Takeo C, et al. Multiple pulmonary nodules in association with pyoderma gangrenosum. Respir Med 1997;91:493-5.

21. Keane J, Gershon S, Wise RP, et al. Tuberculosis associated with infliximab, a tumor necrosis factor alpha-neutralizing agent. N Engl J Med 2001;345:1098-104

22. Gomez-Reino JJ, Carmona L, Valverde VR, Mola EM, Montero MD, BIOBADASER Group. Treatment of rheumatoid arthritis with tumor necrosis factor inhibitors may predispose to significant increase in tuberculosis risk: A multicenter active-surveillance report. Arthritis Rheum 2003;48:2122-7.

23. Wood KL, Hage CA, Knox KS, et al. Histoplasmosis after treatment with anti-tumor necrosis factor-alpha therapy. Am J Respir Crit Care Med 2003;167:1279-82.

24. Vavricka SR, Wettstein T, Speich R, Gaspert A, Bachli EB. Pulmonary granulomas after tumor necrosis factor alpha antagonist therapy. Thorax 2003;58:278-9.

25. Alrashid AI, Brown RD, Mihalov ML, Sekosan M, Pastika BJ, Venu RP. Crohn's disease involving the lung: Resolution with infliximab. Dig Dis Sci 2001;46:1736-9.

26. Casey MB, Tazelaar HD, Myers JL, et al. Noninfectious lung pathology in patients with Crohn's disease. Am J Surg Pathol 2003;27:213-9.

27. Sample C, Bailey RJ, Todoruk D, et al. Clinical experience with infliximab for Crohn's disease: The first 100 patients in Edmonton, Alberta. Can J Gastroenterol 2002;16:165-70.

28. Colombel J-F, Loftus EV Jr, Tremaine WJ, et al. The safety profile of infliximab in patients with Crohn's disease: The Mayo Clinic experience in 500 patients. Gastroenterology 2004;126:19-31. 


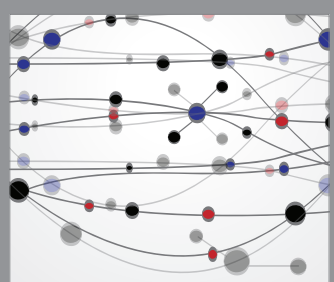

The Scientific World Journal
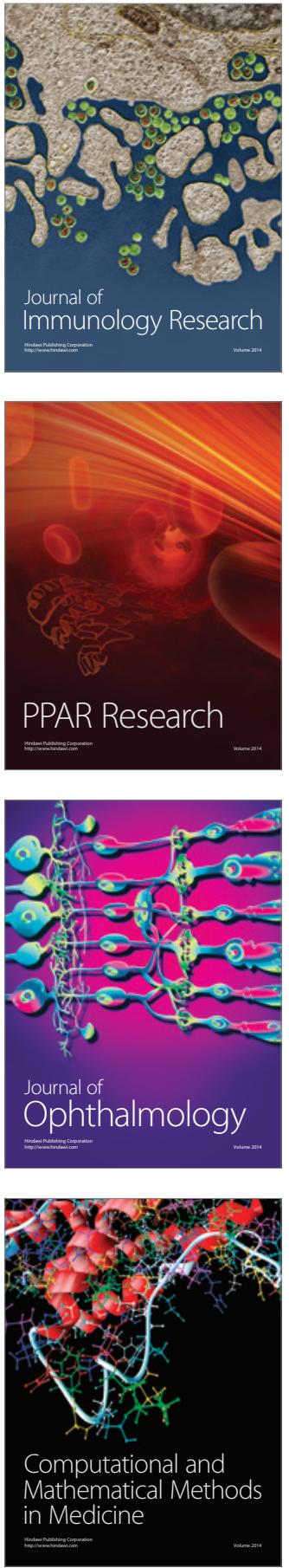

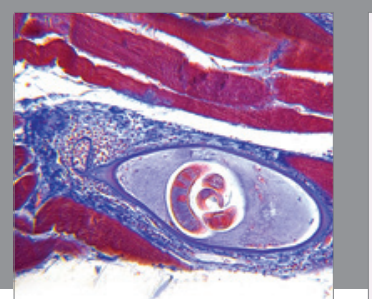

Gastroenterology Research and Practice

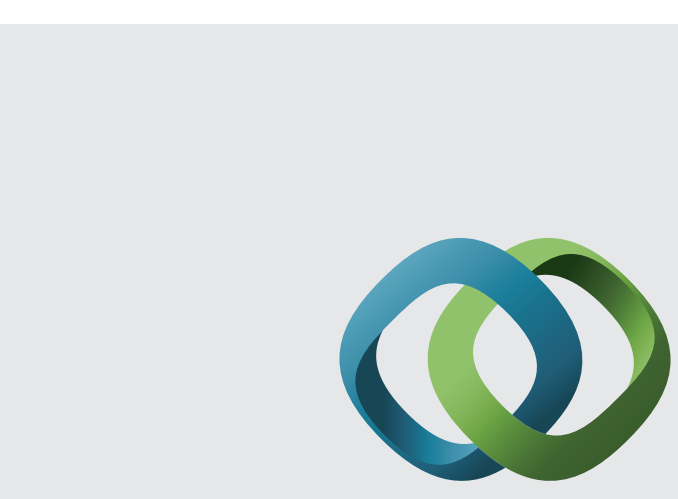

\section{Hindawi}

Submit your manuscripts at

http://www.hindawi.com
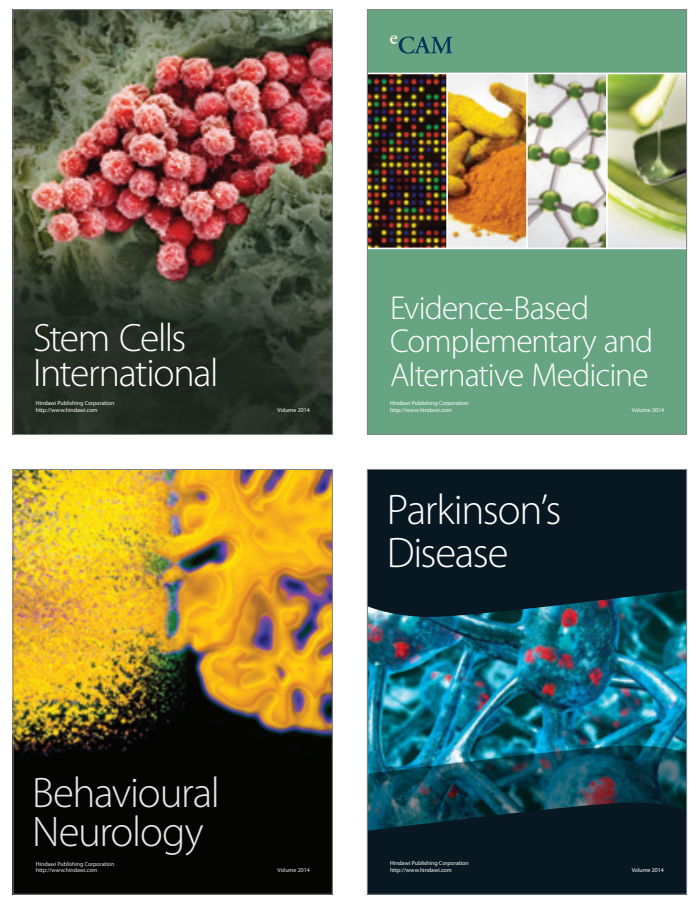
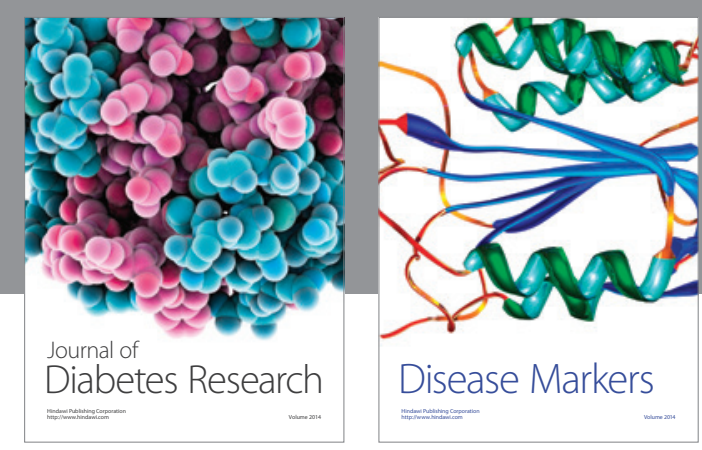

Disease Markers
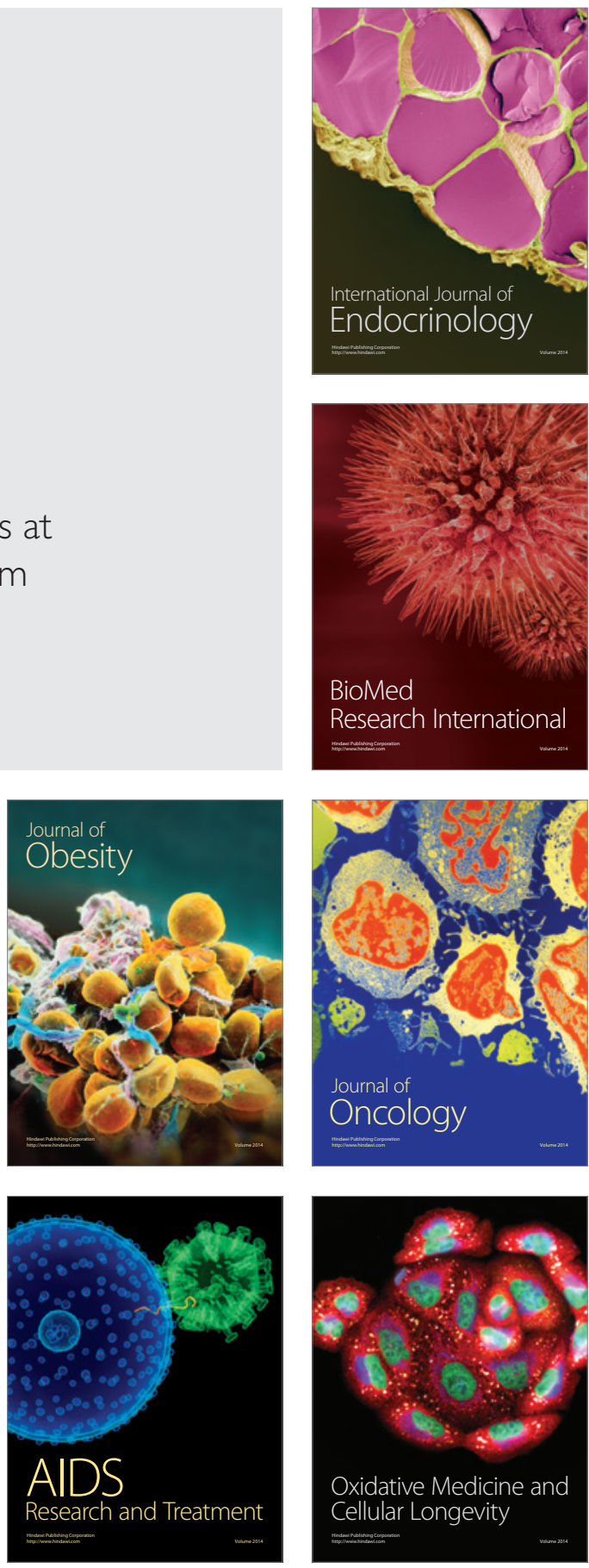